This document is confidential and is proprietary to the American Chemical Society and its authors. Do not copy or disclose without written permission. If you have received this item in error, notify the sender and delete all copies.

\title{
In-Cell Protein Structures from 2D NMR Experiments
}

\begin{tabular}{|r|l|}
\hline Journal: & The Journal of Physical Chemistry Letters \\
\hline Manuscript ID & jz-2016-01074z.R2 \\
\hline Manuscript Type: & Letter \\
\hline Date Submitted by the Author: & 01 -Jul-2016 \\
\hline Complete List of Authors: & $\begin{array}{l}\text { Müntener, Thomas; Universität Basel, Chemie } \\
\text { Häussinger, Daniel; Universität Basel, Chemie } \\
\text { Selenko, Philipp; Leibniz Institute of Molecular Pharmacology, Structural } \\
\text { Biology } \\
\text { Theillet, François-Xavier; CNRS, Institute of Integrative Biology of the Cell }\end{array}$ \\
\hline
\end{tabular}

SCHOLARONE
Manuscripts 
3 AUTHOR NAMES.

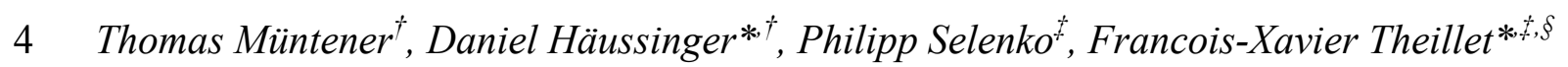

$6 \quad$ 'Department of Chemistry, University of Basel, St. Johanns-Ring 19, 4056 Basel, Switzerland,

$7{ }^{\ddagger}$ Department of Structural Biology, Leibniz Institute of Molecular Pharmacology (FMP Berlin),

8 Robert Roessle Str. 10, 13125 Berlin, Germany

\section{Corresponding Author}

$11 *$ daniel.haeussinger@unibas.ch

12 *francois-xavier.theillet@cnrs.fr 
1 ABSTRACT.

2 In-cell NMR spectroscopy provides atomic resolution insights into the structural properties of 3 proteins in cells, but it is rarely used to solve entire protein structures de novo. Here, we

4 introduce a paramagnetic lanthanide-tag to simultaneously measure protein pseudocontact shifts 5 (PCSs) and residual dipolar couplings (RDCs) to be used as input for structure calculation 6 routines within the Rosetta program. We employ this approach to determine the structure of the 7 protein G B1 domain (GB1) in intact Xenopus laevis oocytes from a single set of 2D in-cell 8 NMR experiments. Specifically, we derive well-defined GB1 ensembles from low concentration 9 in-cell NMR samples $(\sim 50 \mu \mathrm{M})$ measured at moderate magnetic field strengths $(600 \mathrm{MHz})$, thus 10 offering an easily accessible alternative for determining intracellular protein structures.

11

12 TOC GRAPHICS

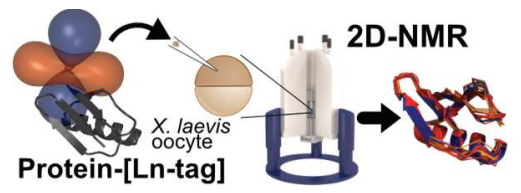

15 KEYWORDS Cellular structural biology, in-cell NMR, protein structure determination, NMR 16 spectroscopy, pseudocontact shifts, residual dipolar couplings. 
1 Physical methods to delineate structural insights into the three-dimensional properties of

2 biomolecules such as X-ray crystallography, NMR spectroscopy or electron microscopy, 3 typically require experimental conditions and sample states that are vastly different from the 4 crowded intracellular environments in which these molecules natively occur ${ }^{1}$. For these reasons, 5 considerable effort is put into the development of biophysical methods to directly study 6 biomolecules inside live cells. While high-resolution X-ray crystallography and single molecule 7 electron microscopy are inherently excluded from such in vivo experiments, due to the 8 requirement of crystalline or vitrified samples and the use of high-energy X-ray or electron 9 beams to generate experimental data, solution NMR spectroscopy can provide non-destructive 10 atomic-resolution information on individual biomolecules in cells. Specifically, in-cell NMR 11 spectroscopy ${ }^{2,3}$ takes advantage of the isotope-labeling effect to selectively 'visualize' isotope12 enriched, NMR-active proteins, RNA or DNA against the backdrop of all other non isotope13 labeled and NMR-inactive intracellular components. This enables direct NMR measurements 14 under truly physiological in vivo conditions. Following this rationale, in-cell NMR has been used 15 to derive insights into intracellular protein conformations, ${ }^{4}$ conformational equilibria, ${ }^{5}$ folding 16 and stability behaviors, ${ }^{6-8}$ protein dynamics, ${ }^{9}$ protein-protein and quinary protein interactions,,${ }^{9,10}$ 17 physiological redox states, ${ }^{11}$ metal-binding properties ${ }^{12}$ and post-translational protein 18 modifications. ${ }^{9,13,14}$ By contrast, the use of in-cell NMR to determine entire protein structures in 19 live cells is generally hampered by the limited lifetimes of in-cell NMR samples, their inherently 20 low concentrations of intracellular, isotope-enriched biomolecules (i.e. protein, RNA or DNA) 21 and their concomitantly poor spectral qualities. Especially lengthy 3D and 4D NMR experiments 22 - commonly used to derive long-range distance restraints for calculating biomolecular structures 23 - suffer from these drawbacks. ${ }^{15}$ Several advances in NMR methods, including faster acquisition 
1 routines and non-uniform sampling procedures ${ }^{16-18}$ have helped to ameliorate some of these

2 shortcomings and enabled the first and only intracellular protein structure to be determined by in-

3 cell NMR spectroscopy in bacteria, although at exceedingly high, non-physiological intracellular

4 protein concentrations in the millimolar range ${ }^{4}$. As a result, and given the general poor sensitivity

5 of 3D and 4D NMR experiments even with such enhancing techniques, comprehensive structure

6 determination efforts of proteins in live cells are deemed impractical and unfeasible. Here, we

7 present an alternative approach to determine intracellular protein structures in live eukaryotic

8 cells that solely relies on 2D NMR experiments and paramagnetic protein tagging to

9 simultaneously induce pseudocontact shifts (PCSs) and residual dipolar couplings (RDCs). In

10 turn, we demonstrate how these structural parameters suffice to calculate high-precision in-cell

11 protein structures with the Rosetta program.

12 Tagging of proteins with different metals of the lanthanide series is known to induce strong

13 metal-specific distance- and orientation-dependent PCS effects on individual NMR-active atomic

14 nuclei. ${ }^{19,20}$ Such PCSs serve as powerful long-range distance restraints in structure calculation

15 routines and they can be derived from simple 2D NMR experiments, with different types of

16 lanthanide-binding protein tags (Fig. 1a). ${ }^{21-24}$ Optimizing the rigidity and linker-lengths of

17 individual tag structures also enables partial alignments of coupled proteins with respect to the

18 external magnetic field, thus giving rise to measurable RDCs and, thereby, additional

19 orientational restraints (Fig. 1b). ${ }^{25-27}$ In a first step, we designed a modified version of the

20 classical tetraaza-carboxylic DOTA chelator, known for its excellent metal coordinating

21 properties, which we termed DOTA-M7Py (Fig. S1). This tag can be covalently coupled to the

22 sulfhydryl moiety of cysteine residues forming a non-reducible thioether bond. ${ }^{28-30}$ With regard

23 to in-cell PCS and RDC measurements, DOTA-M7Py displays several attractive features. First, 
1 it is inherently rigid and adopts exclusively the square anti-prismatic $\Lambda(\delta \delta \delta \delta)$ stereo-confi-

2 guration for the $4 S, 3 R$-Lu derivative. ${ }^{31}$ Second, it is neutral after binding to lanthanide metals.

3 Third, its linker portion is short, which reduces tag mobility and generates larger PCS effects,

4 thus providing higher precision structural information. Fourth, it features both hydrophilic and

5 hydrophobic properties (Fig. S1), which augment stable positioning on most protein surfaces,

6 further enhancing PCSs. Fifth, its thioether bond is expected to withstand the reducing

7 environment of the cytoplasm while maintaining DOTA's outstanding affinity towards

8 lanthanide metals $\left(\mathrm{Kd}<10^{-25} \mathrm{M}\right){ }^{27}$

9 We initially prepared diamagnetic DOTA-M7Py[Lu], and paramagnetic DOTA-M7Py[Tm]

10 and DOTA-M7Py[Tb] complexes, which we coupled to the Streptococcal protein G B1 domain

11 (GB1) via cysteine residues that we introduced by site-directed mutagenesis at individual GB1

12 positions, i.e., E19C, K28C and E42C. Using purified GB1 samples we recorded $2 \mathrm{D}{ }^{1} \mathrm{H}^{15}{ }^{15}$

13 HSQC spectra at $600 \mathrm{MHz}$, which revealed the expected PCS effects for the paramagnetic

14 species (up to 6 p.p.m., Fig. 1a; Fig. S2 \& S3; Table S1). We also detected strong cross-peak

15 splitting in $2 \mathrm{D}{ }^{1} \mathrm{H}_{-}{ }^{15} \mathrm{~N}$ IPAP-HSQC spectra due to paramagnetic alignment of the GB1 domain

16 and resulting RDC effects ${ }^{32}$ (amplitudes reaching $25 \mathrm{~Hz}$ at $293 \mathrm{~K}, 600 \mathrm{MHz}$, Fig. 1b; Fig. S2 \&

17 S4; Table S2). In agreement with the temperature dependency of the tag's mobility, we obtained

$1830 \%$ higher or lower PCS and RDC values at $277 \mathrm{~K}$ and $310 \mathrm{~K}$, respectively (Table S1 \& S2).

19 Moreover, NMR spectra of the different DOTA-M7Py[Tm]-tagged GB1 samples (E19C, K28C

20 and E42C) revealed both positive and negative PCSs, as well as larger overall RDCs, ${ }^{19,20}$ which

21 is particularly useful for structure calculation routines. Therefore, we resorted to using DOTA-

22 M7Py[Tm]-GB1 samples in all further experiments. 
1 Next, we microinjected tagged GB1 carrying either diamagnetic $(\mathrm{Lu})$ or paramagnetic metals 2 (Tm) into Xenopus laevis oocytes for in-cell NMR measurements. ${ }^{3,33,34}$ We recorded $2 \mathrm{D}{ }^{1} \mathrm{H}^{-15} \mathrm{~N}$ 3 HSQC spectra at effective NMR concentrations of $\sim 25 \mu \mathrm{M}$ (intracellular GB1 concentrations $4 \sim 50 \mu \mathrm{M}$ ), which revealed PCSs that were virtually indistinguishable from the respective in vitro 5 samples with an overall RMSD of 0.04 p.p.m., corresponding to 24 and $2.4 \mathrm{~Hz}$ in the ${ }^{1} \mathrm{H}$ and ${ }^{15} \mathrm{~N}$ 6 dimensions, respectively (Fig. 1e; Fig. S2, S5 \& S6). We did not detect sample degradation or 7 metal leakage for up to 24 hours, thus indicating the excellent stability of metal-loaded DOTA-

8 M7Py in Xenopus oocytes. Similarly, we measured in-cell RDCs that were comparable to those 9 obtained in vitro (Fig. 1d-1e, Fig. S7, Table S1 \& S2). Because intracellular viscosity leads to 10 faster T2 relaxation and, accordingly, enhanced ${ }^{15} \mathrm{~N}$ signal decays, we chose to record in-cell 11 RDC experiments with the ${ }^{15} \mathrm{~N}$ free-induction decay (FID) set to $36 \mathrm{~Hz}$, as opposed to $17 \mathrm{~Hz}$ for 12 RDC measurements in vitro (cf Material and Methods). This resulted in average GB1 ${ }^{15} \mathrm{~N}$ line 13 widths of $\sim 30 \mathrm{~Hz}$, compared to $\sim 12 \mathrm{~Hz}$ in vitro, which, concomitantly, increased the RMSD of 14 RDCs measured in vitro versus in cells by $5 \mathrm{~Hz}$, explaining also the larger differences of PCS 15 and RDC RMSDs.

16

17 


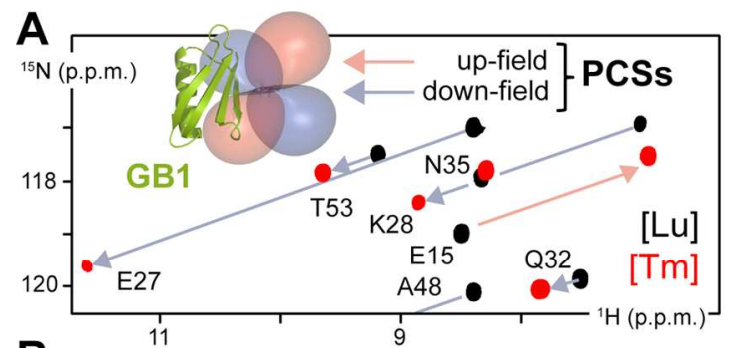

Figure 1. (A) Superposition of ${ }^{1} \mathrm{H}_{-}{ }^{15} \mathrm{~N}$ 2D NMR spectra of purified GB1(E19C) coupled to DOTAM7Py carrying diamagnetic Lutetium (Lu, black) or paramagnetic Thulium (Tm, red). Pseudocontact

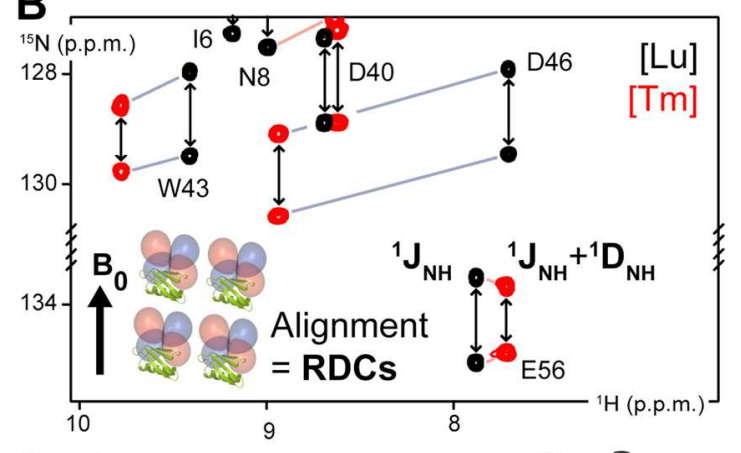
shift (PCS)-induced up- and down-field chemical shift changes are indicated (subset view). The inset depicts the GB1(E19C) ribbon structure (green) with paramagnetic iso-surfaces drawn at 2 p.p.m. (blue \&

C

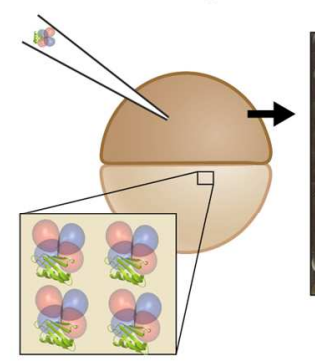

microinjection into Xenopus laevis oocytes

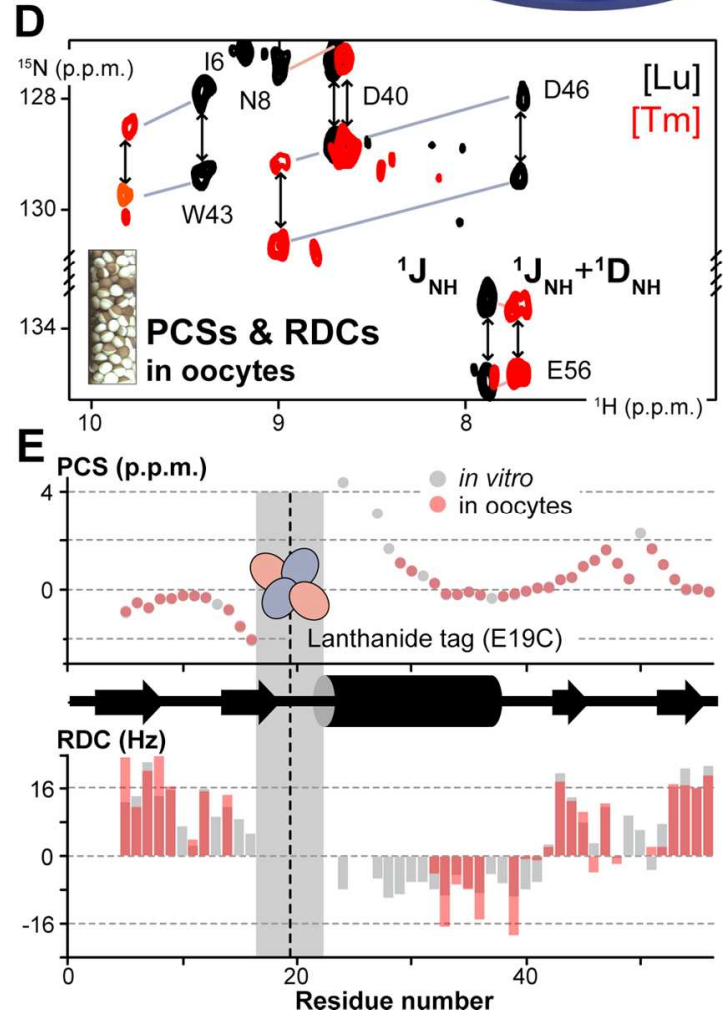

red) (B) Superposition of 2D IPAP-HSQC spectra of GB1 with peak splitting due to amide scalar- $\left({ }^{1} J_{\mathrm{NH}}\right)$ and residual dipolar-coupling (RDC, i.e. $\left.{ }^{1} \mathrm{D}_{\mathrm{NH}}\right)$. Paramagnetic GB1 alignment with respect to the external magnetic field $\left(\mathrm{B}_{0}\right)$ is shown schematically. (C) Overview of GB1 sample preparation in Xenopus oocytes and (D) superposition of GB1 NMR spectra displaying in-cell PCS and RDC effects (at $600 \mathrm{MHz}$ ). (E) Residue-resolved quantification of in vitro \& in-cell PCS and RDC data at $293 \mathrm{~K}$ and $600 \mathrm{MHz}$. 
Finally, we used in-cell PCS and RDC data as input for GPS-Rosetta, a program that integrates

2 PCSs from multiple paramagnetic centers into unified distance constraints in structure

3 calculation routines. ${ }^{23}$ Following the fragment-based rationale used by Rosetta, we generated

4 input libraries of 3- and 9-residue fragments of known protein structures, excluding the structure

5 of GB1 and homologous folds. Using these fragments, we generated 10,000 GB1 structures, out

6 of which we collected the 100 lowest-energy models and compared their conformations to

7 experimentally determined GB1 structures, i.e. X-ray crystallography (PDB code: 2 QMT ${ }^{35}$ ) and

8 solution NMR (PDB code: $1 \mathrm{~GB} 1^{36}, 2 \mathrm{PLP}^{37}$ ). We found poor convergence of individual models,

9 with a median backbone C $\alpha$ RMSD of $1.85 \AA$ (Fig. 2a). Next, we added a PCS-based 'weight-

10 ing' function to steer GB1 models towards conformations that recapitulated the measured values.

11 We used 72, 86 and 96 PCS constraints from the E19C, K28C and E42C GB1 mutants,

12 respectively, and obtained a substantially improved convergence of GB1 structures. The newly

13 determined average C $\alpha$ RMSD of the 100 lowest-energy models was $0.98 \AA$, and $0.64 \AA$

14 between the closest model and the crystal structure (Fig. 2b). Lastly, we used the RDC module of

15 Rosetta to include measured RDCs as additional input in our structure calculation routines,

16 which yielded a similar improved convergence of GB1 models (average C $\alpha$ RMSD of $1.04 \AA$ for

17 the 100 lowest-energy structures, $0.64 \AA$ for the closest model and the X-ray structure) (Fig. 2c).

18 Upon closer inspection of the 10 lowest energy structures, we noticed a remarkable difference

19 between structures obtained with PCS data alone and the ones for which PCS and RDC values

20 were used. In both ensembles, loop L1 (residues N8 to E15) connecting strands $\beta 1$ and $\beta 2$ of

21 GB1 displayed two distinct conformations. One identical to the X-ray structure with an average

$22 \mathrm{C} \alpha \mathrm{RMSD}$ of $1.1 \AA$, and one with a larger C $\alpha$-deviation and average RMSD of 1.6 $\AA$. In PCS

23 models, only three out of ten structures adopted the X-ray L1 conformation. In PCS+RDC 
1 models, five out of ten structures did. Previous solution NMR data indicated that L1 is highly

2 flexible with backbone order parameters $\left(\mathrm{S}^{2}\right)$ in the range of 0.5-0.6 $\left(\mathrm{S}^{2}\right.$ of $\mathrm{GB} 1$ regions with

3 secondary structure $\sim 0.8) .{ }^{37-40}$ These in vitro solution conformations of L1 are similar to those

4 observed in GB1 crystals with an L1 Ca RMSD of $1.35 \AA$ (Fig. 2D). From this we concluded

5 that combined PCS and RDC data from single 2D in-cell NMR experiments are sufficient to

6 determine well-defined protein structures within PCS Rosetta. Our results further confirmed that

7 the overall structural features of GB1 in Xenopus oocytes are similar to those observed in vitro. ${ }^{34}$

8

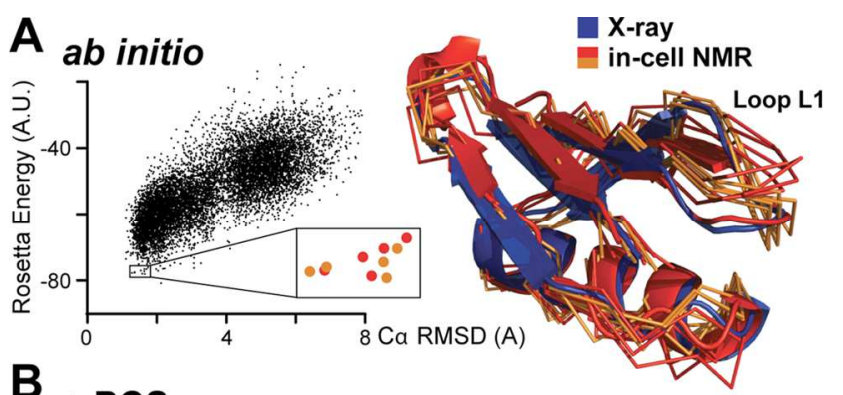

Figure 2. In vitro and in-cell structures of GB1. Scatter plots depict Rosetta energy scores and C $\alpha$ RMSDs of 10,000 GB1 models compared to the GB1 X-ray structure

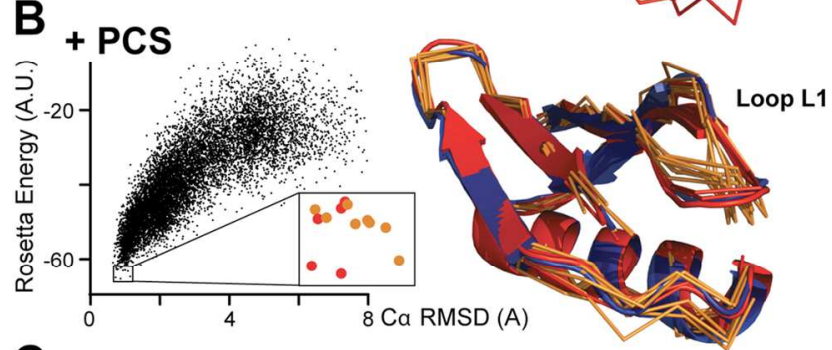
(2QMT). 10 lowest-energy structures are magnified and color-coded according their loop L1 conformations (red/orange). A

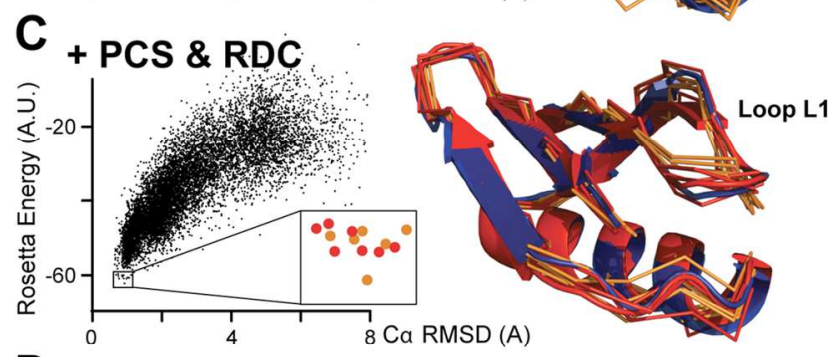
superposition of their structures with the crystal conformation (blue) is shown on the right. GB1 models with L1 conformations corresponding to the one of the GB1 crystal

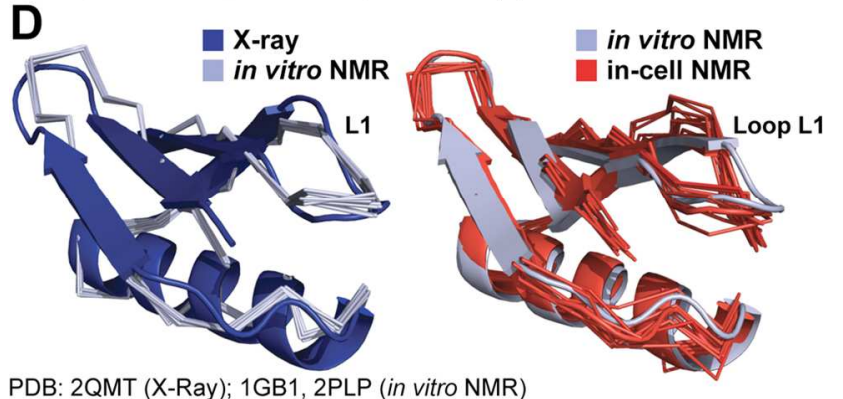
are shown in red, deviating L1 conformers are colored orange. (A) Ab initio GB1 models without using experimental restraints, (B) GB1 models calculated with PCS and (C) 
1 PCS+RDC input data. Rosetta energies contain different energy components and are not

2 comparable. (D) Left: Superposition of high-resolution in vitro solution NMR structures of

3 isolated GB1, i.e. $2 \mathrm{PLP}^{37}$ (dark blue, ribbon representation) and $1 \mathrm{~GB} 1^{36}$ (light blue, ensemble

4 representation). Right: Superposition of 2PLP (blue) and 10 lowest-energy in-cell GB1 models

5 (PCS+RDC, red).

6 In summary, we show that in-cell NMR-derived PCS and RDC data suffice to solve a protein's

7 structure inside cells. Whereas PCS effects decrease with the distance to the coordinated metal,

8 RDCs are distance-independent and offer valuable structural information for residues distal to

9 the paramagnetic center. PCS and RDC data can jointly be obtained from single 2D NMR

10 experiments on in-cell NMR samples of low intracellular protein concentrations, measured at

11 moderate magnetic field strengths, which makes them easily accessible and highly useful. The

12 presented approach can further be used for determining glycan and nucleic acid structures, ${ }^{2,41}$ as

13 well as to probe ligand interactions. ${ }^{42}$ In addition, the high rigidity of the DOTA-M7Py tag

14 renders it a useful tool for in-cell EPR studies. ${ }^{43,44}$ Given that the intracellular delivery of

15 paramagnetically tagged proteins into cultured mammalian cells by electroporation is

16 straightforward, ${ }^{9}$ combined PCS and RDC measurements in live cells also hold great promise for

17 future structure determination efforts in intact mammalian specimens.

19 Supporting Information.

20 The Supporting Information is available free of charge on the ACS Publications website. It

21 contains Material and Methods, Supporting Figures and Tables, in pdf format.

\section{Present Addresses}


$1 \S$ Department of Structural Biology, Institute of Integrative Biology of the Cell (I2BC) - UMR

2 9198, CNRS/CEA/Paris-Saclay University, CEA Saclay Bât. 144, 91191 Gif-sur-Yvette, France.

\section{Funding Sources}

4 This work was supported by the Agence Nationale pour la Recherche, grant ANR-14-ACHN-

5 0015-01 (FXT) and the Fondation Claude et Giuliana, Vaduz, Liechtenstein (TM). PS is

6 supported by an ERC Consolidator Grant \#647474 NeuroInCellNMR.

\section{Notes}

8 Any additional relevant notes should be placed here.

9 The authors declare no competing financial interests.

\section{Acknowledgement}

11 We thank M. van Rossum for laboratory management, and H. Naumann for her kind

12 hospitality. Calculations were performed at the sciCORE scientific computing core facility

13 (http://scicore.unibas.ch/) at the University of Basel. Support by M.Jacquot and K. Arnold is

14 gratefully acknowledged. We thank C.E. Housecroft and E.C. Constable for helpful discussions

15 and R.A. Byrd for providing chemicals.

\section{References}

18 (1) Theillet, F.-X.; Binolfi, A.; Frembgen-Kesner, T.; Hingorani, K.; Sarkar, M.; Kyne, C.;

19 Li, C.; Crowley, P. B.; Gierasch, L.; Pielak, G. J.; et al. Physicochemical Properties of Cells and 20 Their Effects on Intrinsically Disordered Proteins (IDPs). Chem. Rev. 2014, 114, 6661-6714. 
1 (2) Hänsel, R.; Luh, L. M.; Corbeski, I.; Trantirek, L.; Dötsch, V. In-Cell NMR and EPR

2 Spectroscopy of Biomacromolecules. Angew. Chem. Int. Ed. 2014, 53, 10300-10314.

3 (3) Freedberg, D. I.; Selenko, P. Live Cell NMR. Annu. Rev. Biophys. 2014, 43, 171-192.

4 (4) Sakakibara, D.; Sasaki, A.; Ikeya, T.; Hamatsu, J.; Hanashima, T.; Mishima, M.;

5 Yoshimasu, M.; Hayashi, N.; Mikawa, T.; Wälchli, M.; et al. Protein Structure Determination in

6 Living Cells by in-Cell NMR Spectroscopy. Nature 2009, 458, 102-105.

7 (5) Ye, Y.; Liu, X.; Xu, G.; Liu, M.; Li, C. Direct Observation of Ca 2 -Induced Calmodulin

8 Conformational Transitions in Intact Xenopus Laevis Oocytes by 19 F NMR Spectroscopy. 9 Angew. Chem. Int. Ed. 2015, 127, 5418-5420.

10 (6) Monteith, W. B.; Cohen, R. D.; Smith, A. E.; Guzman-Cisneros, E.; Pielak, G. J. Quinary 11 Structure Modulates Protein Stability in Cells. Proc. Natl. Acad. Sci. USA 2015, 112, 1739121742.

13 (7) Danielsson, J.; Mu, X.; Lang, L.; Wang, H.; Binolfi, A.; Theillet, F.-X.; Bekei, B.; Logan, 14 D. T.; Selenko, P.; Wennerstrom, H.; et al. Thermodynamics of Protein Destabilization in Live 15 Cells. Proc. Natl. Acad. Sci. U.S.A. 2015, 112, 12402-12407.

16 (8) Luchinat, E.; Barbieri, L.; Rubino, J. T.; Kozyreva, T.; Cantini, F.; Banci, L. In-Cell 17 NMR Reveals Potential Precursor of Toxic Species From SOD1 fALS Mutants. Nat. Commun. $18 \mathbf{2 0 1 4}, 5,5502$.

19 (9) Theillet, F.-X.; Binolfi, A.; Bekei, B.; Martorana, A.; Rose, H. M.; Stuiver, M.; Verzini, 20 S.; Lorenz, D.; van Rossum, M.; Goldfarb, D.; et al. Structural Disorder of Monomeric A21 Synuclein Persists in Mammalian Cells. Nature 2016, 530, 1-19. 
1 (10) Majumder, S.; Xue, J.; DeMott, C. M.; Reverdatto, S.; Burz, D. S.; Shekhtman, A.

2 Probing Protein Quinary Interactions by in-Cell Nuclear Magnetic Resonance Spectroscopy. 3 Biochemistry 2015, 54, 2727-2738.

4 (11) Barbieri, L.; Bertini, I.; Luchinat, E.; Secci, E.; Zhao, Y.; Banci, L.; Aricescu, A. R. 5 Atomic-Resolution Monitoring of Protein Maturation in Live Human Cells by NMR. Nat. Chem. 6 Biol. 2013, 9, 297-299.

7 (12) Banci, L.; Barbieri, L.; Bertini, I.; Cantini, F.; Luchinat, E. In-Cell NMR in E. Coli to 8 Monitor Maturation Steps of hSOD1. PLoS ONE 2011, 6, 1-8.

9 (13) Selenko, P.; Frueh, D. P.; Elsaesser, S. J.; Haas, W.; Gygi, S. P.; Wagner, G. In Situ 10 Observation of Protein Phosphorylation by High-Resolution NMR Spectroscopy. Nat. Struct. 11 Mol. Biol. 2008, 15, 321-329.

12 (14) Binolfi, A.; Limatola, A.; Verzini, S.; Kosten, J.; Theillet, F.-X.; May Rose, H.; Bekei, 13 B.; Stuiver, M.; van Rossum, M.; Selenko, P. Intracellular Repair of Oxidation-Damaged A14 Synuclein Fails to Target C-Terminal Modification Sites. Nat. Commun. 2016, 7, 10251.

15 (15) Rosato, A.; Vranken, W.; Fogh, R. H.; Ragan, T. J.; Tejero, R.; Pederson, K.; Lee, H.-W.; 16 Prestegard, J. H.; Yee, A.; Bin Wu; et al. The Second Round of Critical Assessment of 17 Automated Structure Determination of Proteins by NMR: CASD-NMR-2013. J. Biomol. NMR $18 \mathbf{2 0 1 5}, 62,413-424$.

19 (16) Waudby, C. A.; Christodoulou, J. An Analysis of NMR Sensitivity Enhancements 20 Obtained Using Non-Uniform Weighted Sampling, and the Application to Protein NMR. J. 21 Magn. Reson. 2012, 219, 46-52. 
1 (17) Hyberts, S. G.; Robson, S. A.; Wagner, G. Exploring Signal-to-Noise Ratio and

2 Sensitivity in Non-Uniformly Sampled Multi-Dimensional NMR Spectra. J. Biomol. NMR 2012, $355,167-178$.

4 (18) Palmer, M. R.; Suiter, C. L.; Henry, G. E.; Rovnyak, J.; Hoch, J. C.; Polenova, T.;

5 Rovnyak, D. Sensitivity of Nonuniform Sampling NMR. J. Phys. Chem. B 2015, 119, 6502$6 \quad 6515$.

7 (19) Otting, G. Protein NMR Using Paramagnetic Ions. Annu. Rev. Biophys. 2010, 39, 3878405.

9 (20) Koehler, J.; Meiler, J. Expanding the Utility of NMR Restraints with Paramagnetic 10 Compounds: Background and Practical Aspects. Prog. Nucl. Magn. Reson. Spectrosc. 2011, 59, $11360-389$.

12 (21) Schmitz, C.; Vernon, R.; Otting, G.; Baker, D.; Huber, T. Protein Structure 13 Determination From Pseudocontact Shifts Using ROSETTA. J. Mol. Biol. 2012, 416, 668-677.

14 (22) Rinaldelli, M.; Ravera, E.; Calderone, V.; Parigi, G.; Murshudov, G. N.; Luchinat, C. 15 Simultaneous Use of Solution NMR and X-Ray Data in REFMAC5 for Joint 16 Refinement/Detection of Structural Differences. Acta Crystallogr. D Biol. Crystallogr. 2014, 70, $17 \quad 958-967$.

18 (23) Yagi, H.; Pilla, K. B.; Maleckis, A.; Graham, B.; Huber, T.; Otting, G. Three19 Dimensional Protein Fold Determination From Backbone Amide Pseudocontact Shifts Generated 20 by Lanthanide Tags at Multiple Sites. Structure 2013, 21, 883-890. 
1 (24) Brewer, K. D.; Bacaj, T.; Cavalli, A.; Camilloni, C.; Swarbrick, J. D.; Liu, J.; Zhou, A.;

2 Zhou, P.; Barlow, N.; Xu, J.; et al. Dynamic Binding Mode of a Synaptotagmin-1-SNARE

3 Complex in Solution. Nat. Struct. Mol. Biol. 2015, 22, 555-564.

4 (25) Salmon, L.; Blackledge, M. Investigating Protein Conformational Energy Landscapes 5 and Atomic Resolution Dynamics From NMR Dipolar Couplings: a Review. Rep Prog Phys $62 \mathbf{2 0 1 5}, 78,126601$.

7 (26) Su, X.-C.; McAndrew, K.; Huber, T.; Otting, G. Lanthanide-Binding Peptides for NMR 8 Measurements of Residual Dipolar Couplings and Paramagnetic Effects From Multiple Angles. 9 J. Am. Chem. Soc. 2008, 130, 1681-1687.

10 (27) Häussinger, D.; Huang, J.-R.; Grzesiek, S. DOTA-M8: an Extremely Rigid, High11 Affinity Lanthanide Chelating Tag for PCS NMR Spectroscopy. J. Am. Chem. Soc. 2009, 131, $12 \quad 14761-14767$.

13 (28) Liu, W.-M.; Skinner, S. P.; Timmer, M.; Blok, A.; Hass, M. A. S.; Filippov, D. V.; 14 Overhand, M.; Ubbink, M. A Two-Armed Lanthanoid-Chelating Paramagnetic NMR Probe 15 Linked to Proteins via Thioether Linkages. Chem. Eur. J. 2014, 20, 6256-6258.

16 (29) Toda, N.; Asano, S.; Barbas, C. F. Rapid, Stable, Chemoselective Labeling of Thiols with 17 Julia-Kocieński-Like Reagents: a Serum-Stable Alternative to Maleimide-Based Protein 18 Conjugation. Angew. Chem. Int. Ed. 2013, 52, 12592-12596.

19 (30) Yang, Y.; Wang, J.-T.; Pei, Y.-Y.; Su, X.-C. Site-Specific Tagging Proteins via a Rigid, 20 Stable and Short Thiolether Tether for Paramagnetic Spectroscopic Analysis. Chem. Commun. $21 \mathbf{2 0 1 5}, 51,2824-2827$. 
1 (31) Opina, A. C. L.; Strickland, M.; Lee, Y.-S.; Tjandra, N.; Andrew Byrd, R.; Swenson, R.

2 E.; Vasalatiy, O. Analysis of the Isomer Ratios of Polymethylated-DOTA Complexes and the

3 Implications on Protein Structural Studies. Dalton Trans. 2016, 4, 4673-4687.

4 (32) Ottiger, M.; Delaglio, F.; Bax, A. Measurement of J and Dipolar Couplings From

5 Simplified Two-Dimensional NMR Spectra. J. Magn. Reson. 1998, 131, 373-378.

6 (33) Hänsel, R.; Luh, L. M.; Corbeski, I.; Trantirek, L.; Dötsch, V. In-Cell NMR and EPR

7 Spectroscopy of Biomacromolecules. Angew. Chem. Int. Ed. 2014, 53, 10300-10314.

8 (34) Selenko, P.; Serber, Z.; Gadea, B.; Ruderman, J.; Wagner, G. Quantitative NMR Analysis

9 of the Protein G B1 Domain in Xenopus Laevis Egg Extracts and Intact Oocytes. Proc. Natl.

10 Acad. Sci. USA 2006, 103, 11904-11909.

11 (35) Schmidt, H. L. F.; Sperling, L. J.; Gao, Y. G.; Wylie, B. J.; Boettcher, J. M.; Wilson, S.

12 R.; Rienstra, C. M. Crystal Polymorphism of Protein GB1 Examined by Solid-State NMR 13 Spectroscopy and X-Ray Diffraction. J. Phys. Chem. B 2007, 111, 14362-14369.

14 (36) Gronenborn, A. M.; Filpula, D. R.; Essig, N. Z.; Achari, A.; Whitlow, M.; Wingfield, P. 15 T.; Clore, G. M. A Novel, Highly Stable Fold of the Immunoglobulin Binding Domain of 16 Streptococcal Protein G. Nature 1991, 253, 657-661.

17 (37) Bouvignies, G.; Meier, S.; Grzesiek, S.; Blackledge, M. Ultrahigh-Resolution Backbone 18 Structure of Perdeuterated Protein GB1 Using Residual Dipolar Couplings From Two Alignment 19 Media. Angew. Chem. Int. Ed. 2006, 45, 8166-8169. 
1 (38) Shapiro, Y. E.; Meirovitch, E. Slowly Relaxing Local Structure (SRLS) Analysis of 15N-

2 H Relaxation From the Prototypical Small Proteins GB1 and GB3. J. Phys. Chem. B 2012, 116, $3 \quad 4056-4068$.

4 (39) Lamley, J. M.; Lougher, M. J.; Sass, H. J.; Rogowski, M.; Grzesiek, S.; Lewandowski, J. 5 R. Unraveling the Complexity of Protein Backbone Dynamics with Combined (13)C and (15)N

6 Solid-State NMR Relaxation Measurements. Phys. Chem. Chem. Phys. 2015, 17, 21997-22008.

7 (40) Vögeli, B.; Kazemi, S.; Güntert, P.; Riek, R. Spatial Elucidation of Motion in Proteins by 8 Ensemble-Based Structure Calculation Using Exact NOEs. Nat. Struct. Mol. Biol. 2012, 19, $9 \quad 1053-1057$.

10 (41) Canales, Á.; Mallagaray, Á.; Berbís, M. Á.; Navarro-Vázquez, A.; Domínguez, G.; 11 Cañada, F. J.; André, S.; Gabius, H.-J.; Pérez-Castells, J.; Jiménez-Barbero, J. Lanthanide12 Chelating Carbohydrate Conjugates Are Useful Tools to Characterize Carbohydrate 13 Conformation in Solution and Sensitive Sensors to Detect Carbohydrate-Protein Interactions. J. 14 Am. Chem. Soc. 2014, 136, 8011-8017.

15 (42) Guan, J.-Y.; Keizers, P. H. J.; Liu, W.-M.; Lohr, F.; Skinner, S. P.; Heeneman, E. A.; 16 Schwalbe, H.; Ubbink, M.; Siegal, G. Small-Molecule Binding Sites on Proteins Established by 17 Paramagnetic NMR Spectroscopy. J. Am. Chem. Soc. 2013, 135, 5859-5868.

18 (43) Martorana, A.; Bellapadrona, G.; Feintuch, A.; Di Gregorio, E.; Aime, S.; Goldfarb, D. 19 Probing Protein Conformation in Cells by EPR Distance Measurements Using Gd 3+Spin 20 Labeling. J. Am. Chem. Soc. 2014, 136, 13458-13465. 
1 (44) Bleicken, S.; Jeschke, G.; Stegmueller, C.; Salvador-Gallego, R.; García-Sáez, A. J.;

2 Bordignon, E. Structural Model of Active Bax at the Membrane. Molecular Cell 2014, 56, 4963505. 